\title{
Optical Fiber Device
}

National Cancer Institute

\section{Source}

National Cancer Institute. Optical Fiber Device. NCI Thesaurus. Code C49954.

A device made with thin glass fibers as a conduit for transmission of light. 